\title{
Design of E-Grant Application Data Warehouse
}

\author{
A.A Ngurah Narendra ${ }^{[1]}$, Santi Ika Murpratiwi ${ }^{[2]}$, and Made Sudarma ${ }^{[3]}$ \\ [1][2] Department of Electrical and Computer Engineering, Post Graduate Program, Udayana University \\ [3] Department of Electrical and Computer Engineering, Udayana University \\ Email: A.A.Narendra@student.unud.ac.id
}

\begin{abstract}
Grants is a program launched by the government as a means to develop the potential of the region or contribute to society in the form of money or objects In submitting as Grant there are many sources of data stored in the system e -Grant, The amount of the proposal Grant is very much in each period so as to be reorganized, One solution for the storage of e-submission of the Grant is to build a data warehouse, Due to the technological development of data warehouse will be able to support the creation of a single access door managerial parties in obtaining information in the data warehouse, The design of the data warehouse were calculated using a four step Kimball, Methods Kimball 4 step has the advantages of a more compact, dynamic, and supports the creation of a data warehouse that is structured output of the data warehouse to the e-Grant in the form of Reports Grant and a recapitulation of Grant where reports Grant is being used as an attachment to a defense in response to the report Expenditure Provincial Bali whereas Summary of Grants used for List SKPD to evaluate the Grant recipient.
\end{abstract}

Index Terms - Design System, Data Warehouse, Grant, Kimball 4 Steps

\section{INTRODUCTION}

With more advanced age and the era of modernization, the more advanced technology and information systems also for processing large amounts of data, According to the International Business Machines Corporation (IBM) on the site, large amounts of data generated by everything around us at all times and large data sets can be implemented in a Database Management System (DBMS) which will be processed to obtain necessary information quickly, accurately, and precious [1] Likewise with a government agency in which requires a fast data processing in determining decision and monitoring the government's performance [2].

This time the problem is where data processing Grant or social assistance (Bansos) is very slow due to the amount of data owned by the Province of Bali and the data entered into the database of the e-Grant is very large and quite a lot so it needs a system that is used as a data warehouse in order to data held by e-Grant not wasted [3].

E-Grant is a program launched by the government as a means to develop the potential of the region [4]. There are many sources of data or databases required in the system settings e Grant, The amount of the Grant proposal that is very much in each period and completeness of data to support e-Grant. making e-Grant committee must always carry out monitoring and evaluation from the reception to the e-Grant reporting, And file management needs to be done to assist in the management of historical data e-Grants to be used for analysis and decisionmaking process of management.

Therefore, the chosen data warehouse to help manage the data history of the e-Grant system. Planning data warehouse built using Kimball 4 Step method. Kimball 4 step method is derived from the Kimball method Step Nine. This method is more concise coined access, dynamic, and supports the creation of a structured data warehouse [5]. Data warehouse planning process is tailored to the business needs of the e-Grant obtained from the interview process to the operator and the management of the e-Grant system. And expected by the e-Grant system, the work of the institutions of governance is facilitated in terms of maintenance Grant and the Grant of transparency of each phase will be undertaken and to facilitate the executive branch of government in analyzing the work process E-Grant system.

\section{STUDI LITERATURE}

\section{A. Literature Review}

Today data warehouse has been developed to assist in the processing of data that is historical, the value of the data are now beginning to be appreciated One study on the design of the data warehouse, is a data warehouse for the national and local tax information comparison [6]. The study discusses the design data warehouse that will be implemented in the tax office to store the data of national taxes and local taxes, with historical data storage can help the government in analyzing the results and the use of state tax.

Other studies that discuss the data warehouse, is the design and implementation of a data warehouse of minor chain supermarkets, data warehouses are widely applied to the retail industry which can be used also for the sales forecasting process with a source of sales history data in the past [7]. The data warehouse also widely applied for the selection of employees or workers in a particular field, this data warehouse serves to store data on the characteristics of an employee who worked in the company [8].

The process of making a matter for student exams also use a lot of data warehouse as a data warehouse provider about when the test is done with a few types of problems and random, it takes a large data warehouse that helps to provide unlucky for students [9]. In addition, the data warehouse with 4 step Kimball method been implemented to build a data warehouse to support the evaluation of the performance of the lecturers at a university [10]. Lecturer evaluated its performance by looking at the ability to work and liveliness not only the faculty evaluation that uses data warehouse, government evaluation is also done by building a data warehouse [2]. In addition to the school and the government, the data warehouse is also 
developed within the enterprise to help analyze the progress of the company and executive information systems Supports [11]. Based on research support and the existing problems in the eGrant system, it will be the design of the data warehouse to support the operational of the e-Grant system.

\section{B. E-Grant Application}

Grants or Bansos is providing assistance in the form of mine from local governments to individuals, families, groups, and communities that are not continuously and selectively to protect people from the possibility of the risk of social [4] in accordance with Regulation Bali provincial No. 29 of 2016.

The flow of these Grant is to bring the proposal through the Community General biro and the protocol Bali provincial secretary will then look for the number and received by the governor of the new bali distributed to organizations (SKPD) new leading subsequently evaluated by SKPD on administration and conditions in the field concerned whether Grant recipients liable to receive Grant Once evaluated, the SKPD convey to the Governor through the Regional Repertory budget team (TAPD) TAPD give consideration SKPD recommendations based on priorities and fiscal capacity, Subsequently it became the basis of the inclusion of the budget allocation of Grant in the Budget Design Public Policy (KUA) and discussed together - together with the Parliament [12].

\section{Data Warehouse}

A data warehouse is a reservoir of the data firm or institution that is structured such that the meaning and for analysis and reporting [13]. It concluded that a data warehouse is a source of information that the data obtained from the Online Transaction Processing (OLTP) [14].

Typically the data warehouse storing the data is historical data warehouse that serves as a comprehensive database that supports all decision analysis required by an organization to provide a summary and detailed information. There are four characteristics in a data warehouse [15], namely:

1. Subject-Oriented

A data warehouse is designed to meet the needs of data analysis based on specific subjects.

2. Integrated

A data warehouse must be able to integrate data from different sources as diverse operating systems therefore before the data from different sources is stored in the data warehouse it should eliminate the existing data inconsistencies.

3. Non-volatile

Data transactions that have been entered into the data warehouse, it will never be updated or deleted (delete) data stored in the data warehouse is not intended for daily activity data from operational systems moved into the data warehouse in a certain time interval tailored to business needs,

4. Time Variant

Data warehouse store history (historical data) Time is a type or piece of data that is crucial in a data warehouse in the data warehouse is often stored various times, such as when the transaction occurred, the time a transaction is changed or when the transaction is canceled, when a transactions can be effective, when a transaction is entered into the computer, and when a transaction is entered into a data warehouse. A data warehouse is said to be good if the data warehouse is worth.

\section{Kimball 4 Step}

The methodology used to produce a good OLAP report is the method Kimball 4 Steps. Kimball 4 steps method is a method derived from Kimball 9 Steps are narrowed so that the process in which a more concise and to the point [5]. Stages in Kimball 4 Steps are as follows.

1. The selection process of

Conduct election process on the subject matter required by the data warehouse

2. grain Selection

Determining exactly what is represented by the fact table record. At this stage will be determined the level of detail of data that can be obtained from the relational model.

3. Make a set of dimensions required to answer all questions in a fact table Set this dimension makes data warehouse is easy to understand and use, the dimension must be described clearly as possible and easy to use dimensions should describe as clearly as possible and strengthen grain dimension tables contain data that describes the dimensions of a business,

4. Selection of facts.

In choosing fact adjusted to a predetermined grain which is prospective facts.

5. Storage pre-calculation disable facts.

At this stage been facts that will fill every table of facts, which facts have to be in accordance with a predetermined grain.

6. Ensuring the dimension tables.

At this stage, the re-examination in the dimension table and add a text description of the dimensions, as well as determine the hierarchy of dimension attributes to simplify the analysis process. Overview of text should be easy to use and understandable by the user.

7. Selection of the duration of the database.

Specify the time period of the database for several years back. In some companies, there is a need to look at the data at the same time, but a year or two years earlier. Very large fact table that caused at least two problems with a significant data warehouse design, namely First, create difficulties for storing old data. The longer the data, the more likely there is a problem in reading and interpreting the old data Secondly, is the use of long dimensions that are important to cause Slowly Changing Dimension (SCD), which will be explained in the next step.

8. Track changes slowly dimensions

Dimensions evolve over time and needs. SCD are three main types:

Type 1, Where change dimension attributes rewritten.

Type 2, Where dimension attribute changes cause the formation of a new dimension record.

Type 3, Where change dimension attributes cause attribute replacement (new collection). Thus, both the old value and the new value of these attributes can be accessed simultaneously on the record of the same dimensions. 
9. Prioritization and query model.

At this stage of physical design considerations, such as the existence of the summary (summary) and aggregate (aggregation). In addition, the problem of administration, backup, performance index and security is also a factor that must be considered. The issue of the draft critical database physically affects the perception of the end users of the data warehouse [4].

Because the process of Kimball 9 steps is considered too long, a problem in applicability and the data in the template is too complex it creates a revision of the method Kimball nine step that Kimball 4 steps. Here are the steps to refine the methodology 9 step into four steps:

1. Choose the business processes (Select the business process to model)

2. Declare granularity business process (Declare the grain of business process)

3. Determine the dimensions of each row fact table (Choose the dimensions that apply to each fact table row)

Identify the facts numerically will fill each row fact table (Identify the numeric fact that will populate each fact table row)

\section{A. Data Source}

\section{RESEARCH METHODOLOGY}

The data used to build the system is the data on the proposed proposal coming into the system (applicants) and data supporting data in the submission of the proposal from the parent process and change.

\section{B. Selection of Business Process}

Business processes will be selected in the design of data warehouse e-Grant system are:

1. The registration process e-Grant system: the registration process at the start of the incoming proposals brought to Apply for Grants.

2. The budgeting process e-Grant system.

Pengangaranya at the start of the funding proposals in allocating how much later after the budget entry in the evaluation of how the new recommendations budget consideration.

3. The admission process/outcome e-Grants: Results from the Report Grant

\section{Flow of E-Grant Application}

Where the system is expected that the proposals entered in the input menu suggestions at the input are no proposal and types of Grants, a new entry in the menu detail the proposal fed the recipient's name Regency / City sub-district, village, Location Details, allotment. New funding proposals how the list of proposals it made in the base by SKPD leading to an evaluation, after the evaluating SKPD leading entitled to enter the system and change of the fund or the designation of her through the menu on how should the funds issued in excess of detail budget or not, entered the stage of recommendation if it is not in accordance with the results of the evaluation in the field, just go to the consideration which the menu this consideration in input how can convey funds for this Grant or not appropriate can remove this phase is the last stage of budgeting Grant if not could possibly be fed in changes in which the plot is listed in Figure 1.

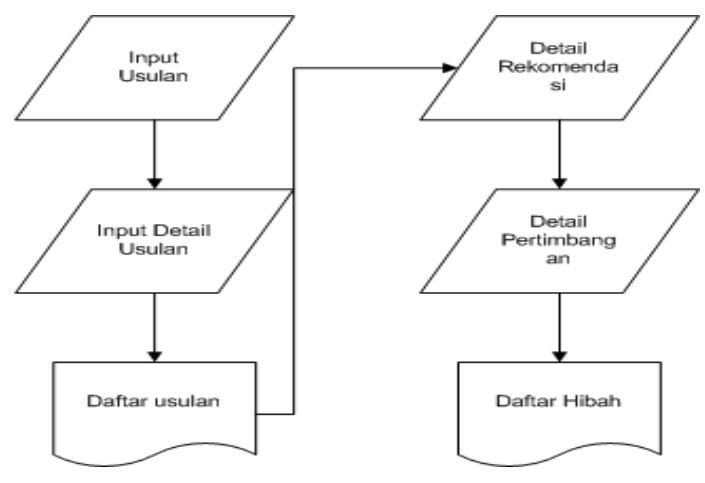

Fig 1. Flow of E-Grant Application

D. Research Stages

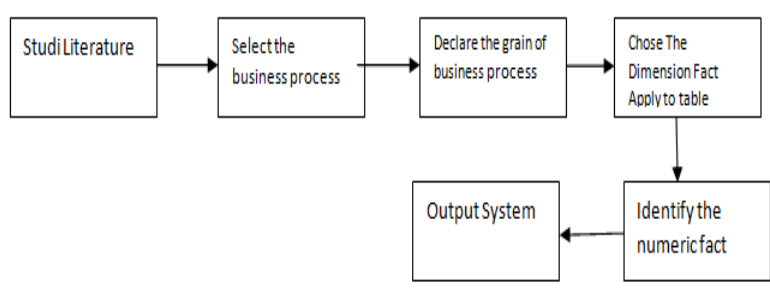

Fig 2. Research Stages

The process of making the system was conducted by interviewing a system user in advance and then implemented by the method of issuing Kimball 4 steps so that the desired Grant data reports as in Figure 2.

\section{RESULTS AND DISCUSSION}

\section{A. Implementation of Kimball 4 Steps}

Here is the process of implementation of Kimball 4 step method.

1. Choosing a business process, where the process of deploying here is the Grant itself to determine in width dimensions and grain a and found the facts of the Grant in the form of a table illustrated in Table 1.

2. State granularity business process wherein after grain found, then formed new database schema and the determined flow of each stage will be designed and depicted in Figure 3.

3. Determine the dimensions for each row of the fact table, then determined for each dimension in the form of the ETL process in which every dimension of his creation of a data warehouse is described in Figure 4.

4. Identify the facts numerical that will fill each row fact table analysis, external factors which make community Grants proposer receives the Grant, and the Grant data transparency.

\section{B. Selection The Grain}


TABLE I

SELECTION THE GRAIN

\begin{tabular}{|l|c|c|c|c|c|c|c|}
\hline \multicolumn{1}{|c|}{ Grain / dimensions } & Time & Identity & $\begin{array}{c}\text { Type of } \\
\text { Grant }\end{array}$ & Organization & SKPD Leading & Allotment & Fund \\
\hline Number of Reg istrants per period & $\mathrm{x}$ & $\mathrm{x}$ & & & & & $\mathrm{x}$ \\
\hline Per Applicant G rant Amount Type & & $\mathrm{x}$ & $\mathrm{x}$ & & & & $\mathrm{x}$ \\
\hline $\begin{array}{l}\text { Number of Reg istrants Per SKPD } \\
\text { Leading }\end{array}$ & & $\mathrm{x}$ & & $\mathrm{x}$ & $\mathrm{x}$ & & $\mathrm{x}$ \\
\hline Number of Applicants Per designation & & & & & & $\mathrm{x}$ & $\mathrm{x}$ \\
\hline Number of Beneficiaries per period & $\mathrm{x}$ & $\mathrm{x}$ & & & & & $\mathrm{x}$ \\
\hline $\begin{array}{l}\text { Number of Beneficiaries Per Grant } \\
\text { Type }\end{array}$ & & $\mathrm{x}$ & $\mathrm{x}$ & & & & $\mathrm{x}$ \\
\hline $\begin{array}{l}\text { Number of Recipients Per SKPD } \\
\text { Leading }\end{array}$ & & $\mathrm{x}$ & & $\mathrm{x}$ & $\mathrm{x}$ & & $\mathrm{x}$ \\
\hline $\begin{array}{l}\text { Number of Beneficiaries Per } \\
\text { designation }\end{array}$ & & & & & & $\mathrm{x}$ & $\mathrm{x}$ \\
\hline Total Beneficiary of the grant & $\mathrm{x}$ & $\mathrm{x}$ & $\mathrm{x}$ & $\mathrm{x}$ & $\mathrm{x}$ & $\mathrm{x}$ & $\mathrm{x}$ \\
\hline
\end{tabular}

Determining exactly what is represented by the fact table record at this stage will be determined the level of detail of data that can be obtained from the models relational.dan its grain is total list has dimension period of time, identity, whereas funds grain number of applicants type of Grant has dimension of identity, kind of Grant funds, while the number of applicants SKPD Leading having dimensions of identity, organization, SKPD Leading fund while grain number of applicants per allotment has dimensions of allotment and funds, the amount type of Grant has dimension of identity, types of Grants and funding, grain number of recipients SKPD Leading having dimensions of identity, organization, SKPD Leading and funds and grain number of recipients per allotment has dimensions of allotment and funds many grains adapted to the number of processes each of the processes will have one grain that would clarify the level of detail of data obtained from a relationship model that can be seen in Figure 3.

\section{Database Structure of E-Grant Application}

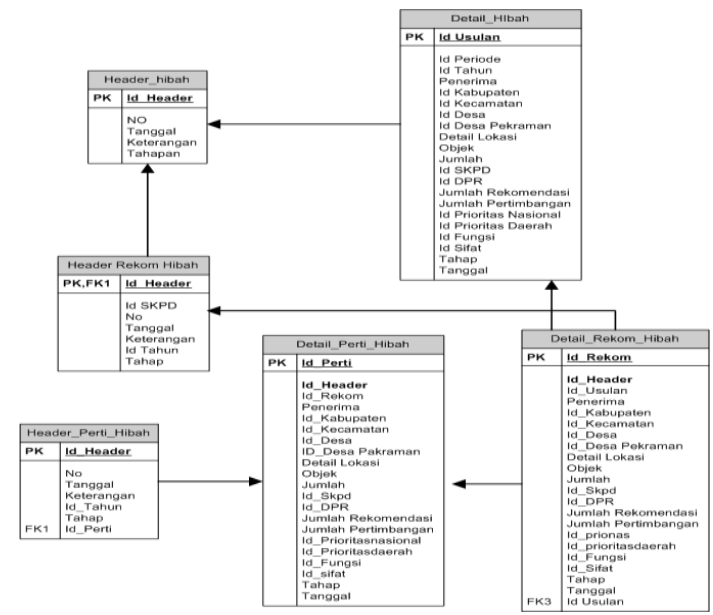

Fig 3. Database Structure

The database structure described in Figure 3 is the structure of the database schema that will be built later in accordance with the flow described in Figure 1 and Figure 2. Where the Table Primary here is Header Grant, Grant and Header_Perti_Grant Header Recommendations.

\section{ETL Process}

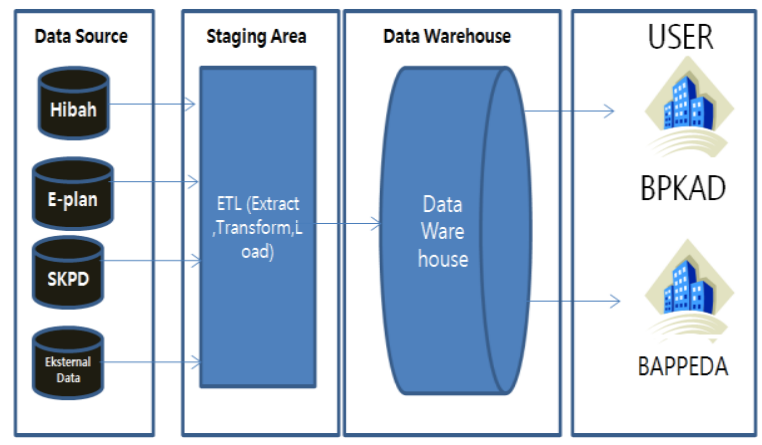

Figure 4. ETL Process

In Figure 4 the process Extract, Transform, Load (ETL) is a process used to process the transfer of data in the database. This phase is also shown all the queries that occur in the data withdrawal.

There is some data that the data input Grants, databases EPlan, the data SKPD and supporting data or external data where the data can be the data that is supporting the Grant Proposal, The next data is entered into the staging area.

Staging areas used to facilitate the integration and cleansing of data so that it can produce high-quality data in the staging area because there is a process for merging the data, cleaning (cleaning) of data and the standardization of data.

Then it went into the data warehouse that data if and produce an output in have by the user can be in the form of graphs, and the data series per year on a data Grant last year and the current year as well as levels - user-level access according to a report in want of system this, before the output results in that the user thanks to the Public Asset Management Agency (BPKAD), and the Regional Development Planning Board (Bappeda).

\section{E. Analysis Process Of Expenditure}

TABLE II

LIST OF BUDGET BALI PROVINCE

\begin{tabular}{|c|l|r|}
\hline No & \multicolumn{1}{|c|}{ Uraian } & \multicolumn{1}{|c|}{ Jumlah (Rp.) } \\
\hline $\mathbf{1}$ & Belanja Tidak Langsung : & $\mathbf{4 . 8 4 2 . 0 4 8 . 3 7 5 . 7 9 3 , 5 0}$ \\
\hline & Belanja Pegawai & $1.830 .777 .811 .604,00$ \\
\hline & Belanja Subsidi Pupuk Organik & $10.000 .000 .000,00$ \\
\hline & Belanja Hibah & $1.073 .267 .400 .000,00$ \\
\hline & Belanja Bansos & $12.640 .400 .000,00$ \\
\hline & Belanja Bagi Hasil & $1.091 .363 .070 .602,50$ \\
\hline & Belanja BKK & $813.999 .693 .587,00$ \\
\hline & Belanja Tak Terduga & $10.000 .000 .000,00$ \\
\hline $\mathbf{2}$ & Belanja Langsung & $\mathbf{1 . 8 1 2 . 2 6 3 . 9 2 0 . 9 1 4 , 0 0}$ \\
\hline & TOTAL & $\mathbf{6 . 6 5 4 . 3 1 2 . 2 9 6 . 7 0 7 , 5 0}$ \\
\hline
\end{tabular}

In Table 2 explained that the Grant include indirect expenditure in addition to spending the rest of the budget expenditure areas where the Grant is set out in Annex 3 the budget and resources of the budget 'expenditures of provincial bali sourced from Revenue (PAD). Budgeting usually lasts twice that in the parent and changes. In holding the funds given the greater because of the initial entry and the remaining 
budgeting evolution where changes smaller funds because the funds are derived from Silva or the results of the program, a program that is not the way to be budgeted back in change.

\section{F. Output of Data Warehouse for e-Grant Application}

The output is issued is have two reports Grant at recapitulation Grant where data Summary of Grants used SKPD to recap the results of the Grant and used to match with the proposal of proposals and reports Grant in use by BPKAD to be input in Appendix budget as a defense response.

To close the shopping area in conjunction with Parliament where output At Grant Report is No. mail, district, sub-district, village, Receivers, and Stages. While in the Summary of Grant output SKPD evaluate Grant From Date How to Date how No. mail, district, sub-district, village, Grantee or community groups that receive these Grant, On behalf of the Grant is given in accordance with the proposals submitted, Position receiver these Grant to communities such as the head or Head indigenous village, and NIP. NIP here used as an ID officer that evaluates Grant or provide recommendations on Grants to be evaluated. For example, Grant the Public Works Department of Roads. All employees who evaluate its NIP field is used as identification and is responsible to Grant in the evaluation.

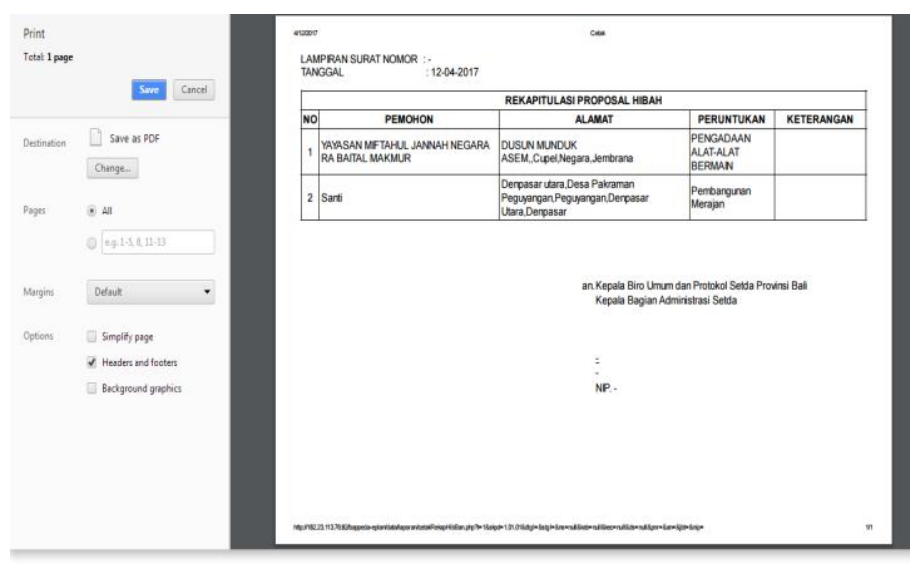

Fig 5. Output expected results

\section{CONCLUSION AND FUTURE WORKS}

A. Conclusion

The design of the data warehouse with four Kimball method step is a step prior to the implementation of the data warehouse,Kimball 4 step method has the advantages of a more compact, dynamic, and supports the creation of a structured data warehouse, The use of a data warehouse is required in the process of e-Grant system administration The design of the data warehouse is in conformity with the requirements of the Provincial Government of Bali because of the design process begins with understanding the flow of e-business Grant and expected data warehouse system's e-Grant to help the government in the evaluation and monitoring of the work process e-Grant in the province of Bali.

For further research is necessary to add a decision support system for the evaluation of SKPD to the Grant, in addition to the need for additional pre-acceptance phase Grant because Grant do not stop at the stage of consideration plus customize (p-issn: 2579-5988, e-issn: 2579-597X) to make the system look more attractive and visible data transparency,E-Grant system can also include circuitry SMS gateway so that Grant determine in more detail the stages of the Grant.

\section{REFERENCES}

[1] T. Oketunji and O. Omodara, "Design of Data Warehouse and Business Intelligence System," no. June, 2011.

[2] H. Chakiri and M. El Mohajir, "A data warehouse for Local Good Governance Monitoring and Assessment - Case Study of Local Registry Office in Morocco," IEEE, pp. 52-58, 2016.

[3] C. Ballard and D. M. Farrell, Dimensional Modeling : In a Business Dimensional Modeling for easier data performance. International Technical Support Organization, 2006.

[4] A. Windarti, "Pengaruh Anggaran Belanja Daerah dan Senjangan Anggaran Terhadap Tingkat Korupsi Di Indonesia," pp. 1-25.

[5] K. U. Kimball Group, Kimball Dimensional Modeling Techniques.

[6] W. Zhijuan, W. Hongchang, and W. Xuefang, "A Data Warehouse Design Method," Int. Conf. Comput. Sci. Serv. Syst. IEEE, pp. 0-3, 2012.

[7] X. Wu and H. Zhang, "Design and Implementation of Data Warehouse of Minor Chain Supermarkets," IEEE, pp. 828-830, 2010.

[8] M. A. Mohammed and M. M. Anad, "Data Warehouse for Human Resource by Ministry of Higher Education and Scientific Research," Int. Conf. Comput. Commun. Control Technol. (I4CT 2014), IEEE, no. I4ct, pp. 176$181,2014$.

[9] N. Pasyeka and M. Pasyeka, "Construction of Multidimensional Data Warehouse for Processing Student's Knowledge Evaluation in Universities," TCSET'2016, IEEE, vol. 1, pp. 7-9, 2016.

[10] N. Kumaladewi and Y. Sugiarti, "Design Analysis of Data Warehouse for Lecturer Performance Evaluation ( Case Study: Faculty of Science and Technology UIN Jakarta )," IEEE, no. 14, 2005.

[11] Y. Ruldeviyani and B. Mohammad, "Design And Implementation Of Merchant Acquirer Data Warehouse at PT . XYZ," IWBIS, pp. 47-50, 2016.

[12] D. K. dan I. P. Bali, "Biro Hukum Bali." 2012.

[13] R. M. Bruckner, B. List, and J. Schiefer, "Developing Requierements for Data Warehouse Systems With Use Cases," Seventh Am. Conf. Inf. Syst., pp. 329-335, 2001.

[14] G. Kimball, Data Warehouse Design Tips. 2011.

[15] R. Kimball, M. Ross, and W. Thornthwaite, The Data Warehouse Lifecycle Toolkit Table of Contents. . 